\title{
Radial Force Control of Multi-Sector Permanent Magnet Machines for Vibration Suppression
}

\author{
G. Valente, IEEE Student Member, L. Papini, A. Formentini, IEEE Member, C. Gerada, IEEE Member, P. \\ Zanchetta, IEEE Senior Member
}

\begin{abstract}
Radial force control in electrical machines has been widely investigated for a variety of bearingless machines as well as for conventional structures featuring mechanical bearings. This work takes advantage of the spatial distribution of the winding sets within the stator structure in Multi-Sector Permanent Magnet machine towards achieving a controllable radial force. An alternative force control technique for Multi-Sector Permanent Magnet machines is presented. The mathematical model of the machine and the theoretical investigation of the force production principle are provided. A novel force control methodology based on the minimization of the copper losses is described and adopted to calculate the $d-q$ axis current references. The predicted performances of the considered machine are benchmarked against Finite Element Analysis. Experimental validation of the proposed control strategy is presented focusing on the suppression of selected vibration frequencies for different rotational speeds.
\end{abstract}

Index Terms-Force Control, Electromagnetic forces, Permanent magnet machines, Brushless motors, Multiphase motors, Optimization methods, Vibration control, Vibration measurement.

\section{NOMENCLATURE}

\section{$p \quad$ Pole pairs.}

$s \quad$ Reference to the generic sector.

$n_{s} \quad$ Number of sectors.

${ }^{s} \Lambda_{P M} \quad$ Permanent magnet flux of one sector $s[\mathrm{~Wb}]$.

$k_{T} \quad$ Torque constant $[N \cdot m / A]$.

$k_{V} \quad$ Voltage constant [V/krpm].

$\vartheta_{e} \quad$ Rotor electrical angular position [rad].

$s^{s} \gamma \quad$ Angular position of one sector $s$ with respect the $x$-axis [rad].

$F_{E, x}, F_{E, y} \quad x-y$ electromagnetic force components [N].

$T_{E} \quad$ Electromagnetic torque $[N \cdot m]$.

$\bar{W}_{E} \quad$ Electromagnetic wrench vector.

${ }^{s} i_{\alpha},{ }^{s} i_{\beta} \quad \alpha-\beta$ currents of one sector $s$ [A].

$\mathbf{K}_{E} \quad$ Electro-magneto-mechanical matrix.

$P_{c u} \quad$ Copper losses [W].

R Electrical resistance matrix.

$R_{p h} \quad$ Electrical resistance of one phase [Ohm].

$B_{r, 0}, B_{\vartheta, 0} \quad$ No load radial and tangential flux density distribution in the airgap [T].

Manuscript received in May 30, 2017; revised in July 15, 2017; accepted in October 29, 2017.

G. Valente, A. Formentini and P. Zanchetta are with the PEMC group University of Nottingham, Nottingham, NG7 2RD, UK (e-mail: giorgio.valente@nottingham.ac.uk).

L. Papini and C. Gerada are with the PEMC group, University of Nottingham and University of Nottingham China campus.
$B_{r, I}, B_{\vartheta, I} \quad$ Incremental radial and tangential flux density distribution in the airgap [T].

$\mathbf{T}_{R} \quad$ Nine-phase transformation matrix from static to rotating reference frame.

\section{INTRODUCTION}

Permanent magnet synchronous motors (PMSMs) are widely adopted in many high performance industrial applications and more recently have seen an increased uptake driven by the transportation market including automotive, railway, marine and aerospace [1], [2]. Application requirements vary from case to case, however there is a general trend towards increasing the power density and the efficiency of the electrical machine aiming a reduction of the system fuel consumption and emission, therefore enhancing the range of operation. Longer lifetime, lower maintenance, higher reliability and lower noise machines are often required in hybrid and full electric automotive applications. As a matter of fact, acoustic noise and mechanical vibrations are an increasingly important design criterion when comes to the optimization of the PMSMs structure [1], [3], [4]. The impact of mechanical bearing on the reliability and maintenance of the electrical machines is typically severe [5], [6]. The active control of the radial forces in such machines could lead to significant improvement in terms of noise reduction and vibration dampening [2], [7][10]. It would also enable the compensation of external forces acting on the rotating structure such as unbalance magnetic pull (UMP), inertial forces and forces of other nature.

The relatively high failure rate of mechanical bearings as well as the oil-free requirement of some applications has pushed the development of bearingless PMSM [11]. This rather recent technology enables the full rotor-dynamic control on the rotating component. The limitation on the maximum rotational speed is therefore defined by the mechanical properties of the rotor constitutive material, enabling the achievement of very high rotational speeds [12]. Active rotor-dynamic control also enables to provide controllable damping effects while crossing critical frequencies.

In bearingless machines, the electromagnetic suspension forces and torque developed can be independently controlled adopting two separate sets of windings [13], [14]. A different approach has been proposed in [15] where suspension forces are generated with a single three-phase winding where each phase current is divided into two parallel paths. A small power converter connected between mid-points of each path provides the current responsible for the lateral force production. Multiphase bearingless motor are also widely adopted for their 
simpler construction, higher power density and better fault tolerance capabilities [16]. As a matter of facts, adopting an ad hoc winding arrangement, it is possible to embed the force and torque capabilities in multiple winding structures. Fiveand seven-phase bearingless motors are analysed in [16], [17] where multiple orthogonal $d-q$ planes are employed for torque and suspension force production. In [18] the force and torque produced in a six-phase slice permanent magnet bearingless motor are controlled by solving an optimization problem that minimizes the Joule losses in the machine.

In the proposed work, an alternative radial force and torque control is applied to a multi-sector PM (MSPM) motor consisting in a conventional 18 slots - 6 poles surface mounted PMSM featuring a re-arranged winding configuration. The distribution of the three-phase windings (sectors) permits to achieve an independent control of $x-y$ forces and of torque over each sector. The modelling and characterization of the MSPM machine is developed in combination with the force/torque control technique. The winding configuration chosen is similar to the one proposed in [19], however the radial force and torque control methods are very different. In [19] the suspension force and torque are considered decoupled and they are produced by $d-$ and $q$-axis current, respectively. A lookup table is employed to obtain the current references that reduce the force ripple. However, the aforementioned work does not consider the optimization of the reference current signals and the crosscoupling between torque and force generation. The latter is taken into account in the novel mathematical model introduced in this work. Then, an optimization method has been employed in order to calculate the reference currents that minimize the copper losses.

The multi-three-phase current components are fed into the system by adopting a set of conventional three-phase inverters in combination with a single control platform. The effectiveness of the control technique proposed is validated through finite elements analysis (FEA). Furthermore, the experimental validation is presented where the force control technique has been applied to damp selected vibrations at different rotor speeds.

\section{Multi-Sector Permanent Magnet Machines}

\section{A. The machine structure}

In Fig. 1, the cross section of the MSPM machine considered in this work is presented. The multi-three phase winding arrangement is highlighted. The main characteristics of the surface mounted MSPM machine are listed in Table I. Each of the three phase sectors has a full-pitched distributed winding with a floating star point. The independent current control for each sector allows for both torque and radial force control.

\section{B. The mathematical model}

The mathematical model of the torque-force characteristic of the machine is derived in a generic form that can be extended to every MSPM machine and it has been detailed in [20]. Assuming that the main spatial harmonic order of PM flux density at the airgap is usually the one related to the pole pairs $(p)$, controllable radial force can be produced

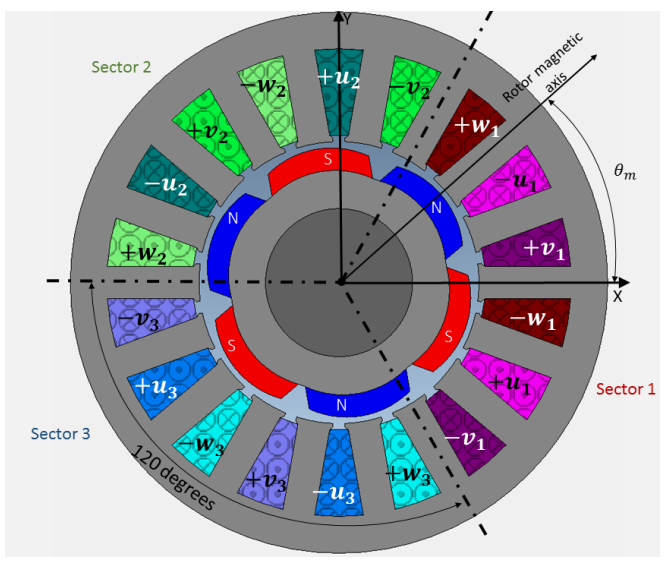

Fig. 1. Cross section of the 18 slot -6 poles 3 sectors PMSM with $3 \times 3$ single layer distributed winding.

TABLE I

MACHINE PARAMETERS

\begin{tabular}{l|l} 
Parameter & Value \\
\hline \hline Pole number $(2 p)$ & 6 \\
PM material & NdFeB \\
Power rating & $1.5[\mathrm{~kW}]$ \\
Rated Speed $\left(\omega_{\text {rated }}\right)$ & $3000[\mathrm{r} / \mathrm{min}]$ \\
Turn/coil & 22 \\
PM flux of one sector $\left({ }^{s} \Lambda_{P M}\right)$ & $0.0284[\mathrm{~Wb}]$ \\
Torque constant $\left(k_{T}\right)$ & $0.128[N \cdot m / A]$ \\
Line to line voltage constant $\left(k_{V}\right)$ & $15.5[\mathrm{~V} / \mathrm{krpm}]$ \\
Outer Stator diameter & $95[\mathrm{~mm}]$ \\
Inner Stator diameter & $49.5[\mathrm{~mm}]$ \\
Axial length & $90[\mathrm{~mm}]$ \\
Airgap length & $1[\mathrm{~mm}]$ \\
Magnets thickness & $4[\mathrm{~mm}]$
\end{tabular}

commanding a magnetic field of order $p \pm 1$. As a matter of facts, the combination of the two above mentioned flux density distributions generates a controllable radial force whose magnitude is in a linear relationship with the armature flux density [21].

Taking advantage of the magnetic decoupling between sectors, considering the geometrical and electromagnetic symmetries featured and under the assumptions of linear magnetic behaviour of the materials, only one machine sector is considered and the superposition principle is applied. The machine under investigation has a number of sectors $n_{s}=p$ which are assumed to be magnetically decoupled. The left superscript $s$ in this manuscript is adopted in order to relate the quantities discusses with the single $s^{\text {th }}$ sector.

The total torque $T_{E}$ results as the algebraic sum of the torque developed by each single sector therefore resulting as $T_{E}=\sum_{s}{ }^{s} T_{E}$. Similarly, the total vector of force $\vec{F}_{E}$ acting on the rotor results as the vector sum of the forces developed by each sector which mathematically results as $\vec{F}_{E}=\sum_{s}{ }_{s} \vec{F}_{E}$. According to the Cartesian reference frame considered, the total force vector can be expressed as the algebraic sum of the projection of ${ }^{s} \vec{F}_{E}$ along each coordinate axis as expressed in (1)

$$
\overrightarrow{F_{E}}=F_{E, x} \hat{\mathbf{x}}+F_{E, y} \hat{\mathbf{y}}=\left(\sum_{s}{ }^{s} F_{E, x}\right) \hat{\mathbf{x}}+\left(\sum_{s}{ }^{s} F_{E, y}\right) \hat{\mathbf{y}}
$$

The simplified model proposed does not account for rotor eccentricity as it is assumed to be rigid, centred and fixed 
by stiff mechanical ball-bearings. Further considerations can be done to include the effect of rotor displacement in the $x-y$ plane [22]. The equivalent description of the electromagnetic quantities in the Clarke reference frame is adopted to simplify the mathematics. The torque and the forces developed by $s^{t h}$ sector of the machine are therefore considered as a function of its current components ${ }^{s} i_{\alpha}$ and ${ }^{s} i_{\beta}$, the electrical angular position $\vartheta_{e}=p \vartheta_{m}$ of the rotor magnetic axis with respect the winding magnetic axis and the geometrical angular position ${ }^{s} \gamma$ of the windings magnetic axis with respect the reference $x$-axis angular position. Introducing the generalized electromagnetic wrench vector ${ }^{s} \bar{W}_{E} \in \mathbb{R}^{n_{m} \times 1}$ [23] of each sector defined by piling the force components ${ }^{s} F_{E, x},{ }^{s} F_{E, y}$ and the electromagnetic torque ${ }^{s} T_{E}$, its pseudo-linear decomposition form leads to the matrix formulation (2) which expresses the mechanical output state function for the $s^{t h}$ sector of the machine.

$$
{ }^{s} \bar{W}_{E}\left(\vartheta_{e},{ }^{s} \gamma,{ }^{s} \bar{i}_{\alpha \beta}\right)={ }^{s} \mathbf{K}_{E}\left(\vartheta_{e},{ }^{s} \gamma\right){ }^{s} \bar{i}_{\alpha \beta}
$$

where ${ }^{s} \mathbf{K}_{E}\left(\vartheta_{e}{ }^{s} \gamma\right)$ is the matrix that characterizes the electromagneto-mechanical output through mapping the current to $\mathrm{x}-\mathrm{y}$ force and torque coefficients while ${ }^{s} \bar{i}_{\alpha \beta}=\left[{ }^{s} i_{\alpha}{ }^{s} i_{\beta}\right]^{T}$ is the vector of the $\alpha-\beta$ axis currents of sector $s$. Considering $n_{m}=3$, the matrix ${ }^{s} \mathbf{K}_{E} \in \mathbb{R}^{3 \times 2}$ can be expressed as (3).

$$
{ }^{s} \mathbf{K}_{E}\left(\vartheta_{e},{ }^{s} \gamma\right)=\left[\begin{array}{cc}
{ }^{s} k_{x, \alpha}\left(\vartheta_{e},{ }^{s} \gamma\right) & { }^{s} k_{x, \beta}\left(\vartheta_{e},{ }^{s} \gamma\right) \\
{ }^{s} k_{y, \alpha}\left(\vartheta_{e},{ }^{s} \gamma\right) & { }^{s} k_{y, \beta}\left(\vartheta_{e},{ }^{s} \gamma\right) \\
{ }^{s} k_{T, \alpha}\left(\vartheta_{e}\right) & { }^{s} k_{T, \beta}\left(\vartheta_{e}\right)
\end{array}\right]
$$

The above consists in a set of coefficient ${ }^{s} k_{*, \times}$ where $*, \times$ defines the wrench and the current components respectively. The elements of the electromagnetic torque constant vector ${ }^{s} \bar{K}_{E, T}\left(\vartheta_{e}\right) \in \mathbb{R}^{1 \times 2}$ are defined in (4).

$$
\left\{\begin{array}{l}
{ }^{s} k_{T, \alpha}\left(\vartheta_{e}\right)=-{ }^{s} k_{T} \sin \left(\vartheta_{e}\right) \\
{ }^{s} k_{T, \beta}\left(\vartheta_{e}\right)={ }^{s} k_{T} \cos \left(\vartheta_{e}\right)
\end{array}\right.
$$

where ${ }^{s} k_{T}=k_{T} \forall s$ is the torque constant resulting identical for each sector of the machine. The electromagnetic torque defined by (4) is not affected by the parameter ${ }^{s} \gamma$ since each sector is considered identical and magnetically independent to the others. On the other hand, the sub-matrix of the electromagnetic forces ${ }^{s} \mathbf{K}_{E, F}\left(\vartheta_{e},{ }^{s} \gamma\right) \in \mathbb{R}^{2 \times 2}$ can be expressed with respect the sub-matrix ${ }^{1} \mathbf{K}_{E, F}\left(\vartheta_{e},{ }^{1} \gamma\right)$ of the reference sector (arbitrary defined, labelled as $s=1$ ). The compact expression of the force-torque characteristic of the $s^{t h}$ sector of the device is reported in (5), suggesting that only one sector has to be characterized with respect the parameter $\vartheta_{e}$ to account for the main aspects of the machine.

$$
{ }^{s} \mathbf{K}_{E}\left(\vartheta_{e},{ }^{s} \gamma\right)=\left[\begin{array}{c}
\mathbf{R}^{T}\left({ }^{s} \gamma\right){ }^{1} \mathbf{K}_{E, F}\left(\vartheta_{e},{ }^{1} \gamma\right) \\
{ }^{s} \bar{K}_{E, T}\left(\vartheta_{e}\right)
\end{array}\right]
$$

The effect of the geometric position of each sector can be accounted introducing the bi-dimensional rotation matrix $\mathbf{R}^{T}\left({ }^{s} \gamma\right)$ expressed in (6).

$$
\mathbf{R}^{T}\left({ }^{s} \gamma\right)=\left[\begin{array}{cc}
\cos \left({ }^{s} \gamma\right) & -\sin \left({ }^{s} \gamma\right) \\
\sin \left({ }^{s} \gamma\right) & \cos \left({ }^{s} \gamma\right)
\end{array}\right]
$$

The expression of the parameter ${ }^{s} \gamma$ for an equally spaced sector structure is defined as ${ }^{s} \gamma=(s-1)\left(2 \pi / n_{s}\right)+\gamma_{0}$, where $\gamma_{0}$ defines the angular position of the magnetic axis of sector 1 with respect to the $x$-axis.

\section{The RAdial Force AND Torque Control Method}

The current commands required to control the $x-y$ force and torque can be determined by evaluating the inverse of matrix $\mathbf{K}_{E}$ that characterizes the overall electro-magnetomechanical output of the machine. The matrix formulation written in (2) can be extended as in (7) in order to include all motor sectors.

$$
\bar{W}_{E}\left(\vartheta_{e}, \bar{\gamma}, \bar{i}_{\alpha \beta}\right)=\mathbf{K}_{E}\left(\vartheta_{e}, \bar{\gamma}\right) \bar{i}_{\alpha \beta}
$$

where the element of the expression are defined as

$\bar{i}_{\alpha \beta}=\left[{ }^{1} i_{\alpha}{ }^{1} i_{\beta} \ldots{ }^{3} i_{\alpha}{ }^{3} i_{\beta}\right]^{T}, \quad \bar{\gamma}=\left[{ }^{1} \gamma \cdots{ }^{3} \gamma\right]$ and $\mathbf{K}_{E}\left(\vartheta_{e}, \bar{\gamma}\right)=\left[{ }^{1} \mathbf{K}_{E}\left(\vartheta_{e},{ }^{1} \gamma\right) \cdots{ }^{3} \mathbf{K}_{E}\left(\vartheta_{e},{ }^{3} \gamma\right)\right]$. In general, the matrix of the generalized wrench coefficients results defined as $\mathbf{K}_{E}\left(\vartheta_{e}, \bar{\gamma}\right) \in \mathbb{R}^{n_{m} \times 2 n_{s}}$ which results in a square matrix only if $2 n_{s}=n_{m}$. As a matter of fact, the dimension of the output electromagnetic wrench vector is smaller than the number of state variables $\left(n_{m}=3<2 n_{s}\right)$, hence a proper strategy has to be adopted in order to obtain reasonable phase current reference signals [18] as described in the following section.

\section{A. Pseudo Inverse matrix}

The conventional control strategies adopted in [19] do not have limitations on the maximum current supplied to each sector. The total current injected in the winding structures has an impact on the magnetic load distribution in the machine as well as the total joule losses which are the major source of heat in electrical machines. The minimization of the losses can have beneficial effect on the overall efficiency of the system, avoiding de-rating due to hotspots as well as reducing the impact of possible magnetic core saturation [24]. The compact expression of the total heat losses is given in (8).

$$
P_{c u}=\bar{i}_{\alpha \beta}^{T} \mathbf{R} \bar{i}_{\alpha \beta}
$$

where $\mathbf{R}$ is the matrix of electrical resistances. Under the assumption of identical electrical resistance of the phases, $\mathbf{R}=$ $\operatorname{diag}\left(R_{p h}\right)$ and therefore (8) reduces to $P_{c u}=R_{p h} \bar{i}_{\alpha \beta}^{T} \bar{i}_{\alpha \beta}$.

The rectangular matrix $\mathbf{K}_{E}\left(\vartheta_{e}, \bar{\gamma}\right)$ introduced in (7) cannot be inverted with conventional techniques. The Moore-Penrose pseudo inverse is considered as the generalization of the in verse matrix and is commonly applied to compute the solution of under- and over-determined system of linear equations. In the specific configuration considered in this work $n_{s}=3$ implying that the system in (7) is under-determined with an infinite number of solutions. Considering that $\mathbf{K}_{E}\left(\vartheta_{e}, \bar{\gamma}\right)$ is full rank for column $\forall \vartheta_{e}$, its pseudo inverse $\mathbf{K}_{E}^{+}\left(\vartheta_{e}, \bar{\gamma}\right)$ can be expressed as in (9).

$$
\mathbf{K}_{E}^{+}\left(\vartheta_{e}, \bar{\gamma}\right)=\mathbf{K}_{E}^{T}\left(\vartheta_{e}, \bar{\gamma}\right)\left[\mathbf{K}_{E}\left(\vartheta_{e}, \bar{\gamma}\right) \mathbf{K}_{E}^{T}\left(\vartheta_{e}, \bar{\gamma}\right)\right]^{-1}
$$


The approximated vector of the current demand required to develop the reference mechanical output $\bar{W}_{E}^{*}$ can be then expressed as in (10).

$$
\bar{i}_{\alpha \beta}^{\prime}=\mathbf{K}_{E}^{+}\left(\vartheta_{e}, \bar{\gamma}\right) \bar{W}_{E}^{*}
$$

The resulting reference current calculated according to the definition of the generalized inverse, results in that quantity which minimizes (8) by means minimizing the currents, therefore achieving a minimum overall losses operative condition.

The online computation of the pseudo inverse matrix $\mathbf{K}_{E}^{+}\left(\vartheta_{e}, \bar{\gamma}\right)$ is a difficult task mainly due to the large amount of operations required. Taking advantage of the full characterization of the machine, each element of matrix $\mathbf{K}_{E}\left(\vartheta_{e}, \bar{\gamma}\right)$ results known and here approximated with their fundamental harmonic waveform. The elements of the pseudo inverse matrix $\mathbf{K}_{E}^{+}\left(\vartheta_{e}, \bar{\gamma}\right)$ is therefore evaluated numerically offline using equation (9) for $\vartheta_{e} \in\{0, \ldots, 2 \pi\}$. The sinusoidal expressions obtained are shown in [20] and they are digitalised in the control platform enabling a drastic reduction of the online computational effort needed.

\section{B. FE force performance evaluation}

The case study machine is modelled in the computational environment (MagNet) and FEA are performed in order to validate the predicted performances.

In [20] the radial force control method has been evaluated by FE simulations choosing different constant force and torque references. However, a sinusoidal force is needed in general to compensate an eventual vibration. Hence, performances of the control strategy considering a time-varying force is presented in this section. In particular, the harmonic decomposition can be applied to the force enabling to concentrate the effort in the compensation of its most severe components. The supplied currents are defined by means of (10) and the FE model is generated in order to take into account the material non-linearities. Fig. 2 a) shows the resultant force produced having chosen rated torque operating condition $\left(T_{E, \text { ref }}=T_{\text {rated }}=5.5[N \cdot \mathrm{m}]\right)$ and a rotating reference force of constant amplitude $|F|$ and frequency $n \vartheta_{m}$ with $n \in \mathbb{N}$. $|F|$ changes with steps from $50[N]$ to $200[N]$ to consider different saturating conditions while, in order to have a whole number of periods for each force step, $n$ is set to 12. Therefore, from Fig. 2 a) it is possible to observe that the $x-y$ force components follow their references for each of the four force steps at 0,90 , 180 and 270 [deg]. Fig. 2 b) shows the torque generation with and without the rotating force production. It can be observed that the force ripple slightly increases with the commanded force magnitude when both force and torque are generated. In particular, when the magnitude of the force generated is $200[\mathrm{~N}]$ (rated value) the force ripple reaches its maximum value $(\simeq 8.5 \%$ bigger than the force ripple without force production). However, in the operating condition considered the machine current exceeds its rated value (both the torque and the force are commanded at their rated value) hence it cannot be achieved in a real implementation. Therefore, it is possible to conclude that the torque generation is not significantly affected by the force control.
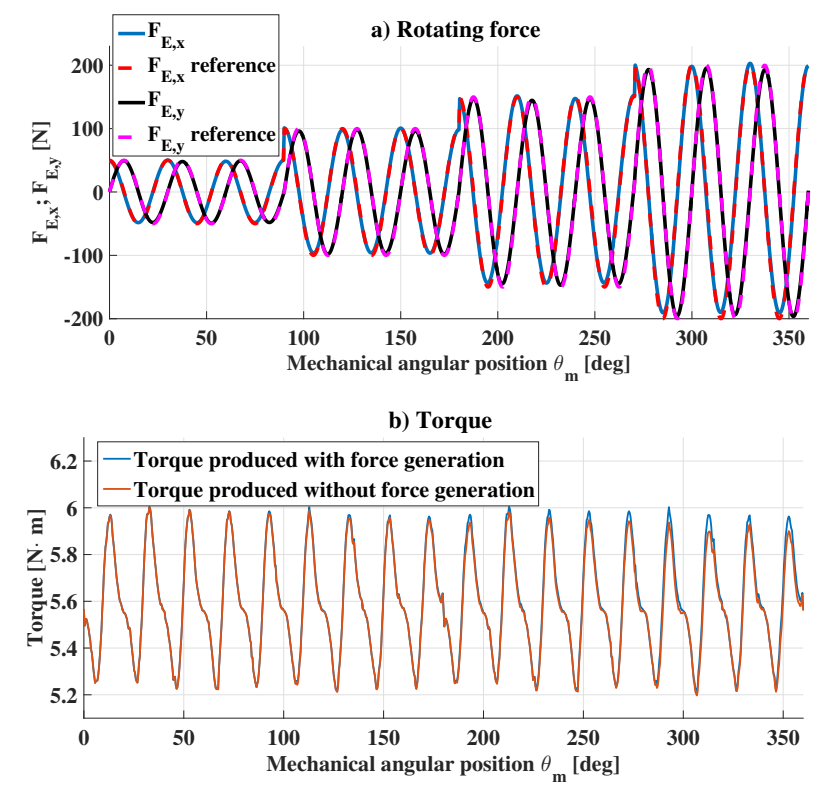

Fig. 2. FE simulation results for rotating force production a) and torque production $\mathrm{b}$ ). The torque production results are obtained considering two operating conditions: with and without force generation.

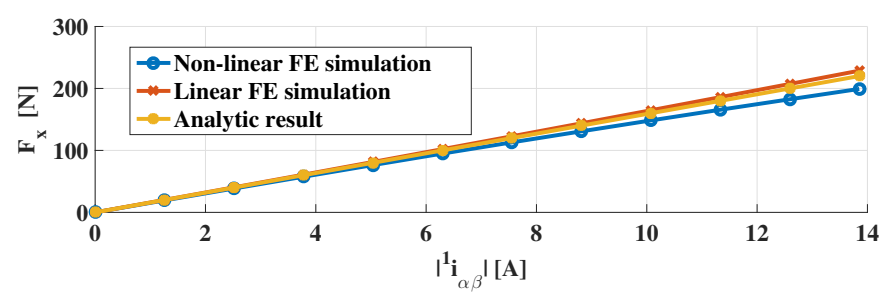

Fig. 3. FE (linear and non-linear) and analytical $x$-axis force trend versus the module of the $\alpha-\beta$ axis current $\left|{ }^{1} i_{\alpha \beta}\right|$ of sector 1 .

The rotor magnetic axis has been aligned with the axis of sector 1 , hence with the $\mathrm{x}$-axis. The $x$-axis force versus the module $\left|{ }^{1} i_{\alpha \beta}\right|$ of the $\alpha-\beta$ axis current of sector 1 is shown in Fig. 3 in the case of non-linear and linear magnetic behaviour of the materials. Furthermore, the analytical result computed according to (10) is also presented. The non-linear FE simulation curve highlights the impact of the material saturation on the forces output. The $185[N]$ computed against the $200[N](+10 \%)$ predicted by means of the analytical calculations enables to characterize the machine performance under high magnetic load considering the maximum current of $13[A]$.

\section{The Machine Characterization}

\section{A. No Load characteristic}

The validation of the voltage constant $k_{V}$ is performed comparing the analytical, FEA and experimental results at no load condition. The machine is driven by means of an external load at various rotational speed within the machine operative range. Both FEA and analytical prediction are computed considering the machine in open circuit condition at different mechanical rotational speed.

Fig. 4 presents the line to line back-EMF waveforms of the three motor sectors at the rated motor speed $\omega_{\text {rated }}$. It can be noticed that same phases in different sectors presents identical 


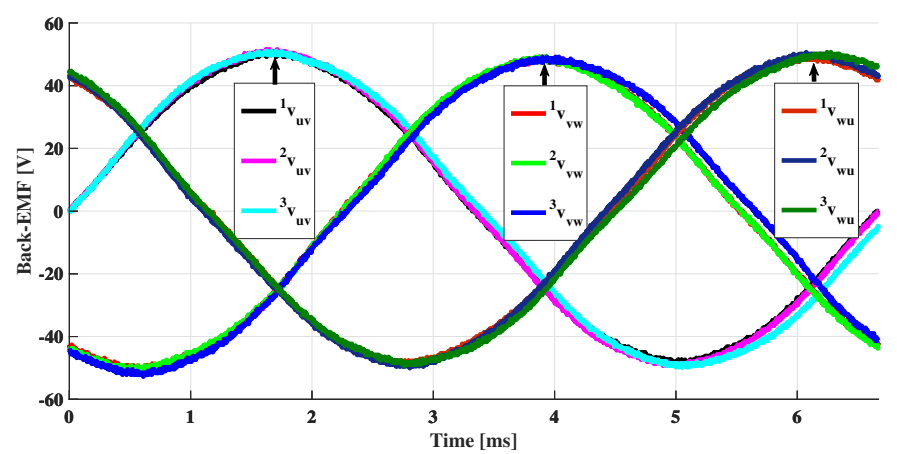

Fig. 4. Experimental line to line back-EMF waveforms of the three sectors of the MSPM motor at $\omega_{\text {rated }}$.

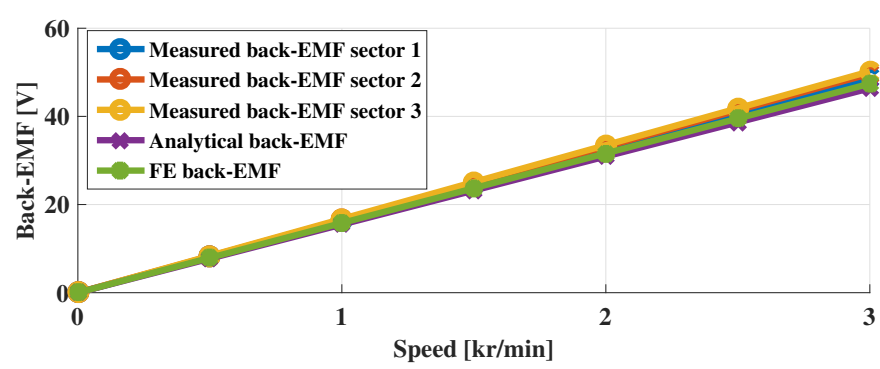

Fig. 5. Comparison between the experimental, FE and analytical back-EMF trends against the rotation speed. The back-EMF between phase $u$ and $v$ of each motor sector has been included in the graph.

back-EMF waveforms since located in equivalent electrical position.

The analytical expression of the line to line voltage constant results $k_{V}=\sqrt{3} \pi p \Lambda_{P M} / 30[\mathrm{~V} / \mathrm{rpm}]$ which results in a good prediction if compared with respect to the experimental and FEA values presented in Fig. 5. Fig. 6 shows the harmonic spectrum of the experimental, FEA and analytical waveform of the back-EMF of one motor phase. The analytical prediction results accurate if considered that the harmonic content of the experimental and FEA waveforms is negligible as it can be observed.

\section{B. The torque capability}

The well-known torque equation under sinusoidal approximation for surface PMSM is reported in (11) referred to the generic $s^{t h}$ sector.

$$
{ }^{s} T_{E}\left({ }^{s} \bar{i}_{\alpha \beta}, \vartheta_{e}\right)=\frac{3}{2} p^{s} \Lambda_{P M}\left(\cos \left(\vartheta_{e}\right)^{s} i_{\beta}-\sin \left(\vartheta_{e}\right)^{s} i_{\alpha}\right)
$$

where ${ }^{s} \Lambda_{P M}$ is the peak fundamental of the no load flux linkage with the winding structure.

Under the assumption of identical sectors, the combination of (4) and (11) leads to the expression of the torque constant that characterizes the elements of ${ }^{s} \bar{K}_{E, T}\left(\vartheta_{e}\right)$ resulting in $k_{T}=$ $3 / 2 p \Lambda_{P M}$. The equivalent formulation of (4) in the reference frame synchronous with the electrical time-varying fields is obtained adopting the Park transformation. Considering only $q-$ axis current supplied for the sector $s$, the developed torque expressed as ${ }^{s} T_{E}=k_{T}{ }^{s} i_{q}$. The trend of the total torque $T_{E}=\sum_{s}{ }^{s} T_{E}$ as a function of the $q$-axis current of each sector is shown in Fig. 7, where the FE simulation results are

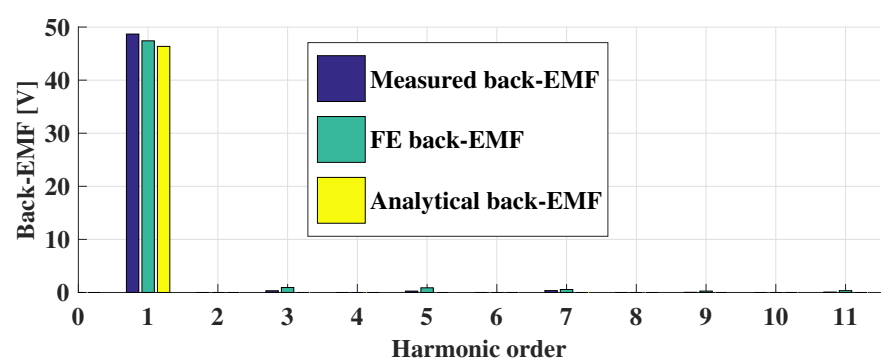

Fig. 6. Comparison of the harmonic spectrum between measured, FE and analytical back-EMFs between phase $u_{1}$ and $v_{1}$.

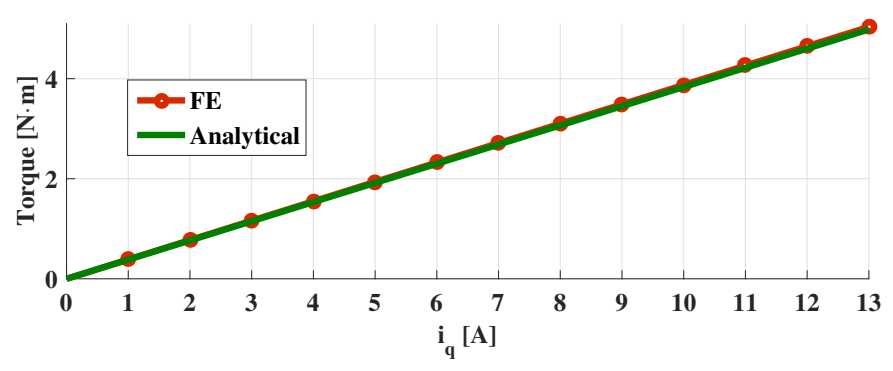

Fig. 7. Analytical and FE torque trend as a function of the $q$-axis current of each motor sector.

compared with the analytical ones. The current limit of each sector $s$ has been set to the rated current of 13 [A].

\section{The force capability}

Considering ${ }^{1} \gamma=0$, the coefficients of the matrix ${ }^{1} \mathbf{K}_{E, F}\left(\vartheta_{e}, 0\right)$ characterises the force capabilities of the device. Each element of the matrix is computed by means FEA and compared with analytical prediction. Two time stepping FE simulations featuring linear magnetic material feeding only the three-phase winding of the reference sector with constant ${ }^{1} \bar{i}_{\alpha \beta}=\left[\begin{array}{ll}1 & 0\end{array}\right]^{T}[A]$ and ${ }^{1} \bar{i}_{\alpha \beta}=\left[\begin{array}{ll}0 & 1\end{array}\right]^{T}[A]$ respectively for the $\alpha$ and $\beta$ coefficients are performed. The simulations are performed for a full rotor electrical revolution.

The analytical evaluation of the coefficients of ${ }^{1} \mathbf{K}_{E, F}\left(\vartheta_{e}, 0\right)$ is performed through the integration of the Maxwell stress tensor along the airgap circumference [25] and the results are compared in Fig. 8. The force-torque coefficient calculations relies on the radial and tangential components of the magnetic flux density at the mid-radius of the airgap which are therefore required. The pseudo-linear decomposition of the magnetic flux density is considered and reported in (12) splitting the no load with respect to the incremental contributions.

$$
\left\{\begin{array}{l}
{ }^{1} B_{r}\left(\alpha, \vartheta_{e}, \bar{i}\right)=B_{r, 0}\left(\alpha, \vartheta_{e}\right)+{ }^{1} B_{r, I}\left(\alpha, \vartheta_{e}, \bar{i}\right) \\
{ }^{1} B_{\vartheta}\left(\alpha, \vartheta_{e}, \bar{i}\right)=B_{\vartheta, 0}\left(\alpha, \vartheta_{e}\right)+{ }^{1} B_{\vartheta, I}\left(\alpha, \vartheta_{e}, \bar{i}\right)
\end{array}\right.
$$

The reference of the angular variable $\alpha$ corresponds with the magnetic axis of the reference sector. The no load components are dependant by means of the stator-rotor relative angular position [26] while the incremental ones consider the effect of current flowing in the three-phase winding [27]. A detailed procedure for the force coefficients calculation is presented in [22].

According to the harmonic spectrum of the coefficient presented in Fig. 9, the first harmonic approximation is considered 


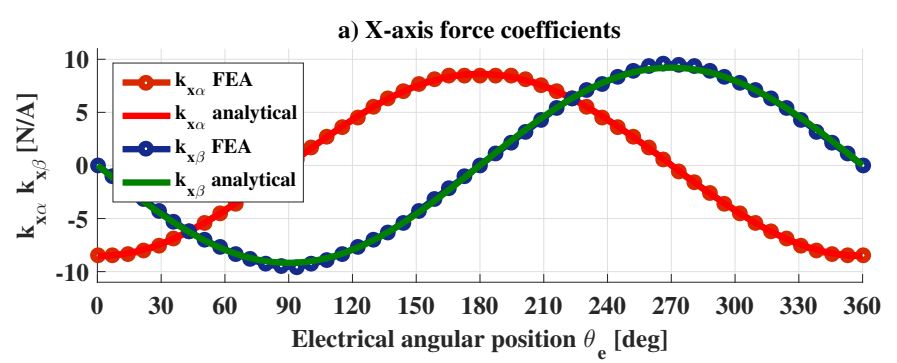

b) Y-axis force coefficients

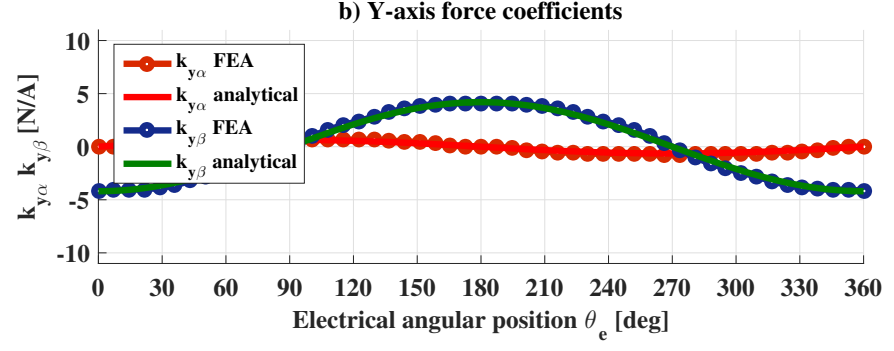

Fig. 8. FE and analytical force coefficient against the rotor electrical angular position.

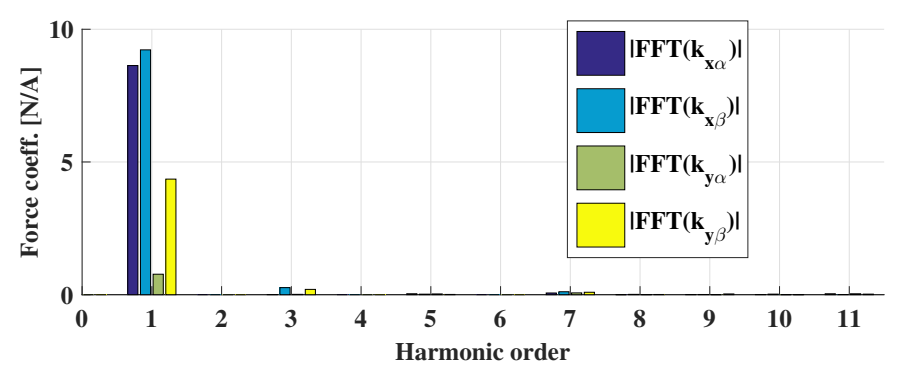

Fig. 9. FFT amplitudes of the force coefficients harmonics considering the waveform carried out through FE simulations.

and the expression for the elements of matrix ${ }^{1} \mathbf{K}_{E, F}\left(\vartheta_{e}, 0\right)$ is reported in (13)

$$
\left\{\begin{aligned}
{ }^{1} k_{x, \alpha}\left(\vartheta_{e}, 0\right) & =\widetilde{k}_{x, \alpha} \cos \left(\vartheta_{e}+\varphi_{x, \alpha}\right) \\
{ }^{1} k_{x, \beta}\left(\vartheta_{e}, 0\right) & =\widetilde{k}_{x, \beta} \cos \left(\vartheta_{e}+\varphi_{x, \beta}\right) \\
{ }^{1} k_{y, \alpha}\left(\vartheta_{e}, 0\right) & =\widetilde{k}_{y, \alpha} \cos \left(\vartheta_{e}+\varphi_{y, \alpha}\right) \\
{ }^{1} k_{y, \beta}\left(\vartheta_{e}, 0\right) & =\widetilde{k}_{y, \beta} \cos \left(\vartheta_{e}+\varphi_{y, \beta}\right)
\end{aligned}\right.
$$

where $\varphi_{*, \times}$ is the phase shift of the force's components and $\widetilde{k}_{*, \times}$ their fundamental amplitude. In Table II the coefficients evaluated for the machine under investigation are reported.

\section{EXPERIMENTAl Results of the Vibration SUPPRESSION}

This section deals with the experimental validation of the proposed force control technique. It has been mentioned in the introduction that the force control can be exploited for several purposes. In this work the force control targets the suppression of specific vibrations that has been detected by means of accelerometer transducers during normal operation of the motor equipped with ball bearings.
TABLE II

FORCE COEFFICIENTS

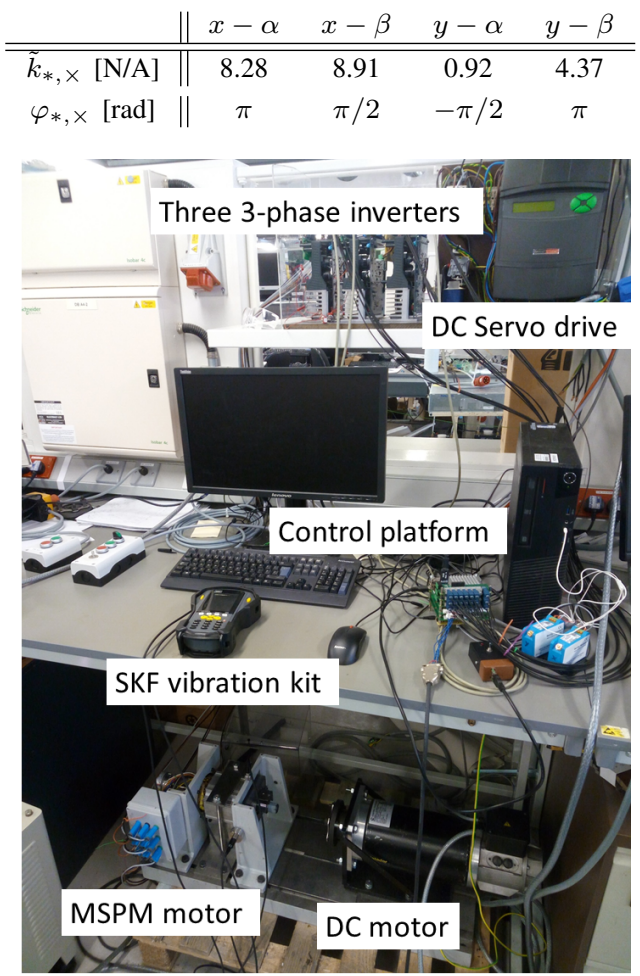

Fig. 10. Experimental set-up in all its parts: MSPM motor, DC motor, SKF vibration kit, control platform, three-phase inverters, DC servo drive.

\section{A. Description of the Experimental set-up}

Fig. 10 details the experimental set-up. A DC permanent magnet motor is aligned with the MSPM machine featuring flexible coupling to establish the connection between the two devices. It features the same rated speed of the MSPM motor and $15[\mathrm{~N} \cdot \mathrm{m}]$ rated torque. A four-quadrant DC servo drive is adopted to control the DC motor in all operating conditions. The level of vibration is measured by means of accelerometers and dedicated signal processing tools. Each of the three 3phase inverters with rated power $2[\mathrm{~kW}]$ feeds one of the MSPM motor winding set. The power module of the single inverter is a "dual-in-line package intelligent power module (PS21A79)" manufactured by Mitsubishi Semiconductor. The switching frequency and dead time of the transistors are set equal to $10[\mathrm{kHz}]$ and $2.2[\mu \mathrm{s}]$, respectively. The industrial control boards mounted on each inverter have been removed and substituted by one centralized control platform that communicates with the power modules gate drives by means of fibre optics cables. The custom made control platform ( $u C u b e)$ is based on the off-the-shelf Microzed board from Avnet, a low-cost development board based on the Xilinx Zynq7000 All Programmable SoC [28]. The Zynq integrates in a single device a dual-core ARM CortexA9 based Processing System (PS) and a Field Programmable Gate Array (FPGA) Programmable Logic (PL) [28].

The $d-q$ axis feedback current control loops of each sector and the speed control loop rely on standard PI controllers. The PIs are tuned in order to achieve a stable, fast and performing control system. The pseudo inverse matrix $\mathbf{K}_{E}^{+}\left(\vartheta_{e}, \bar{\gamma}\right)$ intro- 


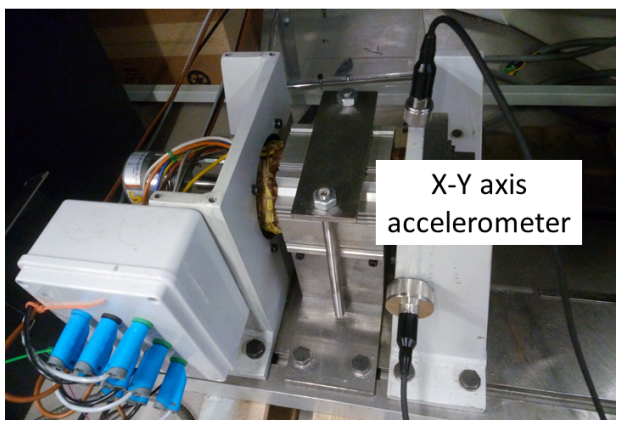

Fig. 11. Detail of the MSPM motor with the $x-y$ axis acceleration transducers mounted on one of the angular plates.

duced in the previous section is adopted to generate the $2 n_{s}$ $\alpha-\beta$ current references from the required $x-y$ forces and torque references. The transformation from static to rotating reference frame is defined by means (14) and applied to (10).

$$
\bar{i}_{d q}^{\prime}=\mathbf{T}_{R}\left(\vartheta_{e}\right) \bar{i}_{\alpha \beta}^{\prime}
$$

The matrix $\mathbf{T}_{R}\left(\vartheta_{e}\right) \in \mathbb{R}^{2 n_{s} \times 2 n_{s}}$ is expressed as in (15)

$$
\mathbf{T}_{R}\left(\vartheta_{e}\right)=\left[\begin{array}{ccc}
\mathbf{R}_{d q}\left(\vartheta_{e}\right) & 0_{2} & 0_{2} \\
0_{2} & \mathbf{R}_{d q}\left(\vartheta_{e}\right) & 0_{2} \\
0_{2} & 0_{2} & \mathbf{R}_{d q}\left(\vartheta_{e}\right)
\end{array}\right]
$$

having $\mathbf{R}_{d q}\left(\vartheta_{e}\right) \in \mathbb{R}^{2 \times 2}$ defined as the clockwise rotation matrix.

\section{B. No Load Vibration Spectrum}

Two acceleration transducers positioned on the angular plate that supports one of the rotor sides as shown in Fig. 11 are adopted to detect the no load vibrations along the $x$ - and $y$ axis. The no load vibration characteristic of the rig is measured controlling the MSPM machine at different rotational speed by means of the speed loop and recording the harmonic spectrum of the signal from the accelerometer probes using the vibration analyser module. The vibration transducer system employed is the SKF Microlog MX vibration kit. Fig. 12 shows the spectrum of the accelerations for several rotor speeds varying from $200[\mathrm{r} / \mathrm{min}]$ up to $3000[\mathrm{r} / \mathrm{min}]$. It can be noticed that the harmonic spectrum presents a peak related with the fundamental rotating frequency followed by frequencies of higher harmonic order. The source of the vibrations are related with the mechanical ball bearing reaction, UMP due to rotor misalignment, encoder mechanical coupling, ripple in the currents, non-symmetric airgap flux density distribution under each motor sector.

Considering the harmonic decomposition of a general disturbance force, (16) defines the general formulation of the vibration source that is aimed to be minimized featuring $\left|F_{k}\right|$ and $\varphi_{k}$ as the unbalanced force amplitude and phase angle respectively.

$$
\left\{\begin{array}{l}
F_{x, k}=\left|F_{k}\right| \cos \left(k \vartheta_{m}+\varphi_{k}\right) \\
F_{y, k}=\left|F_{k}\right| \sin \left(k \vartheta_{m}+\varphi_{k}\right)
\end{array} \quad ; k=1,2,3, \ldots, \infty\right.
$$

Unbalanced forces rotating at $k$ times the rotor mechanical speed are considered and the main harmonics for different orders $k$ are highlighted with red continuous lines in Fig. 12.

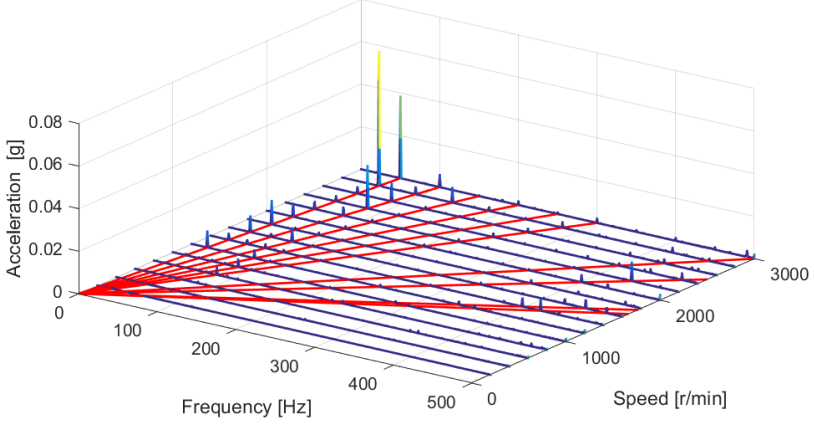

Fig. 12. No load vibrations waterfall plot

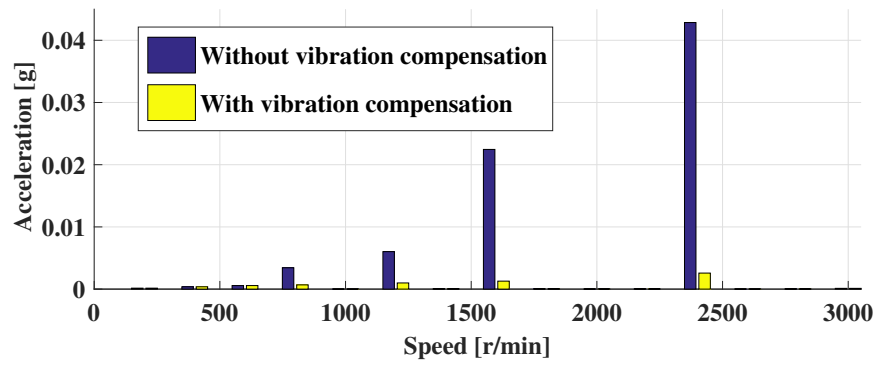

Fig. 13. $80[\mathrm{~Hz}]$ vibration harmonic amplitudes for different speeds with and without vibration suppression.

\section{Vibration suppression}

In Section III the radial force control technique has been presented and validated through FE simulations. In this section the force control has been exploited to suppress specific harmonics of the vibration spectrum. In particular, Fig. 13 shows that the $80[\mathrm{~Hz}]$ vibration harmonic features high peaks for several rotating speed. The four highest peaks have been chosen as target of the vibration suppression. The selected unbalanced force to compensate are defined by means of (16) where $k$ equal to $6,4,3,2$ for $800[\mathrm{r} / \mathrm{min}]$, $1200[\mathrm{r} / \mathrm{min}], 1600[\mathrm{r} / \mathrm{min}]$ and $2400[\mathrm{r} / \mathrm{min}]$, respectively. Hence, the amplitude $\left|F_{k}\right|$ and the phase angle $\varphi_{k}$ are the two parameters required to define the force components of the reference $\bar{W}_{E}^{*}$. The measurement of the effect of the forces leads to the problem of determine the above mentioned coefficients which are therefore manually identified observing the changes in the vibration harmonic spectrum amplitude provided by the SKF Microlog vibration analyzer. Fig. 13 and Fig. 14 presents the compensation results achieved while in Table III, the parameters used for the vibration suppression are listed.

Another relatively high vibration peak can be found in Fig. 12 at $440[\mathrm{~Hz}]$ for $2200[\mathrm{r} / \mathrm{min}]$ rotation speed. An attempt to suppress the vibration has been done and the result is shown in Fig. 14.

\section{Post-processing analysis}

The fast Fourier transform (FFT) applied to the measured and reference current of sector 1 is compared with their analytical expression in Fig. 16 a)-h). It can be observed that the $d-q$ axis currents required to produce the reference rotating force 


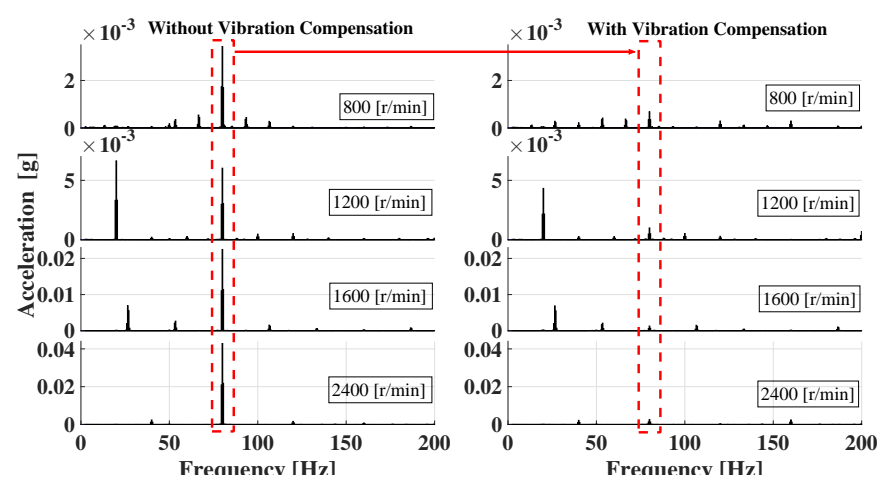

Fig. 14. Suppression of the $80[\mathrm{~Hz}]$ vibration at 800 [r/min], $1200[\mathrm{r} / \mathrm{min}]$ 1600 [r/min] and 2400 [r/min].

TABLE III

VIBRATION SUPPRESSION PARAMETERS

\begin{tabular}{c||c|c|c|c|}
$\omega_{m}[\mathrm{r} / \mathrm{min}]$ & 800 & 1200 & 1600 & 2400 \\
\hline$|F|[N]$ & 35 & 55 & 47 & 120 \\
\hline$\gamma[\mathrm{deg}]$ & 220 & 230 & 80 & 100
\end{tabular}

consist of a main harmonic at the desired frequency $k f_{\text {rot }}$ and two secondary harmonics. The explanation for this phenomena can be found in the analytical expression of the $d-q$ axis reference currents. It can be easily obtained substituting (10) into (14) and replacing $\bar{W}_{E}^{*}$ with the expressions of the rotating force references given in (16) and the torque reference $T_{r e f}$. For the sake of brevity only the analytical expression of the reference $d-q$ axis current of sector 1 is reported in (17).

$$
\left\{\begin{array}{l}
i_{d 1}=\left[k_{d}\left(\varphi_{k}\right)+k_{d+}\left(\varphi_{k}\right)+k_{d-}\left(\varphi_{k}\right)\right]\left|F_{k}\right| \\
i_{q 1}=\left[k_{q}\left(\varphi_{k}\right)+k_{q+}\left(\varphi_{k}\right)+k_{q-}\left(\varphi_{k}\right)\right]\left|F_{k}\right|-k_{T}^{\prime} T_{r e f}
\end{array}\right.
$$

The coefficients $k_{d}, k_{d+}$ and $k_{d-}$ are reported in (18)

$$
\left\{\begin{array}{l}
k_{d}\left(\varphi_{k}\right)=\frac{\left(k_{1}+k_{3}\right)}{2} \cos \left(\vartheta_{e} \frac{k}{p}+\varphi_{k}\right) \\
k_{d+}\left(\varphi_{k}\right)=\frac{\left(k_{1}-k_{2}-k_{3}-k_{4}\right)}{4} \cos \left(\vartheta_{e}\left[\frac{k}{p}+2\right]+\varphi_{k}\right) \\
k_{d-}\left(\varphi_{k}\right)=\frac{\left(k_{1}+k_{2}-k_{3}+k_{4}\right)}{4} \cos \left(\vartheta_{e}\left[\frac{k}{p}-2\right]+\varphi_{k}\right)
\end{array}\right.
$$

while coefficients $k_{q}, k_{q+}$ and $k_{q-}$ are detailed in (19)

$$
\left\{\begin{array}{l}
k_{q}\left(\varphi_{k}\right)=\frac{\left(k_{4}-k_{2}\right)}{2} \sin \left(\vartheta_{e} \frac{k}{p}+\varphi_{k}\right) \\
k_{q+}\left(\varphi_{k}\right)=\frac{\left(-k_{1}+k_{2}+k_{3}+k_{4}\right)}{4} \sin \left(\vartheta_{e}\left[\frac{k}{p}+2\right]+\varphi_{k}\right) \\
k_{q-}\left(\varphi_{k}\right)=\frac{\left(k_{1}+k_{2}-k_{3}+k_{4}\right)}{4} \sin \left(\vartheta_{e}\left[\frac{k}{p}-2\right]+\varphi_{k}\right)
\end{array}\right.
$$

Finally, $k_{1}, k_{2}, k_{3}$ and $k_{4}$ are the amplitudes of the coefficients of $\mathbf{K}_{E}^{+}\left(\vartheta_{e}\right)$ related to sector 1 only.

$$
\mathbf{K}_{E, 1}^{+}\left(\vartheta_{e}\right)=\left[\begin{array}{ccc}
k_{1} \cos \left(\vartheta_{e}\right) & k_{2} \sin \left(\vartheta_{e}\right) & k_{T}^{\prime} \sin \left(\vartheta_{e}\right) \\
k_{3} \sin \left(\vartheta_{e}\right) & k_{4} \cos \left(\vartheta_{e}\right) & -k_{T}^{\prime} \cos \left(\vartheta_{e}\right)
\end{array}\right]
$$

where $k_{T}^{\prime}=1 /\left(n_{s} k_{T}\right)[A / N \cdot m]$.

In equations (18) and (19) the amplitudes and frequencies of the aforementioned harmonics are presented. The same calculations can be done for sector 2 and 3 obtaining an

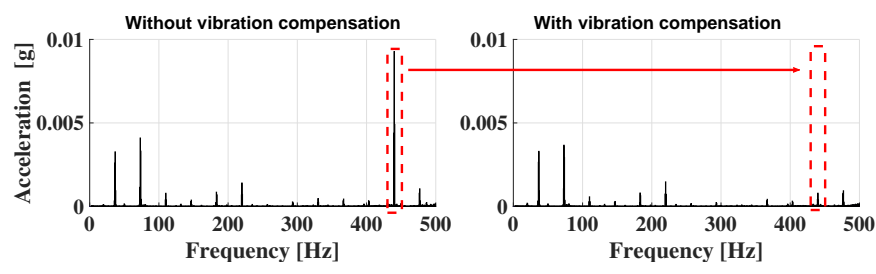

Fig. 15. Suppression of the $440[\mathrm{~Hz}]$ vibration at $2200[\mathrm{r} / \mathrm{min}]$.
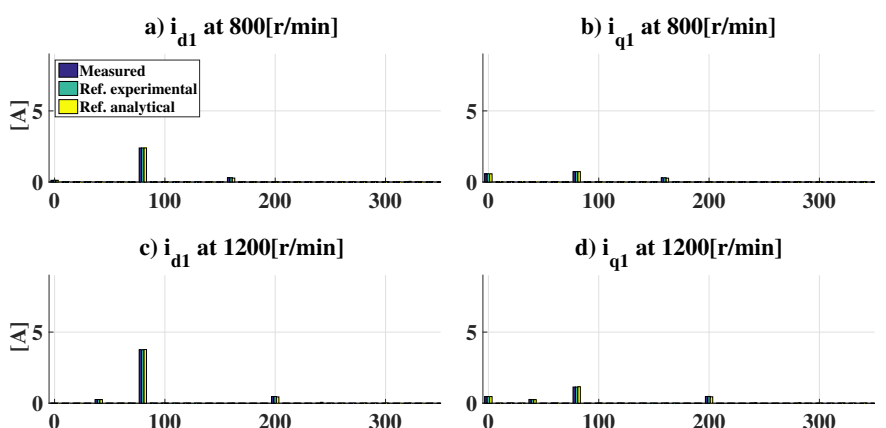

d) $i_{q 1}$ at $1200[\mathrm{r} / \mathrm{min}]$
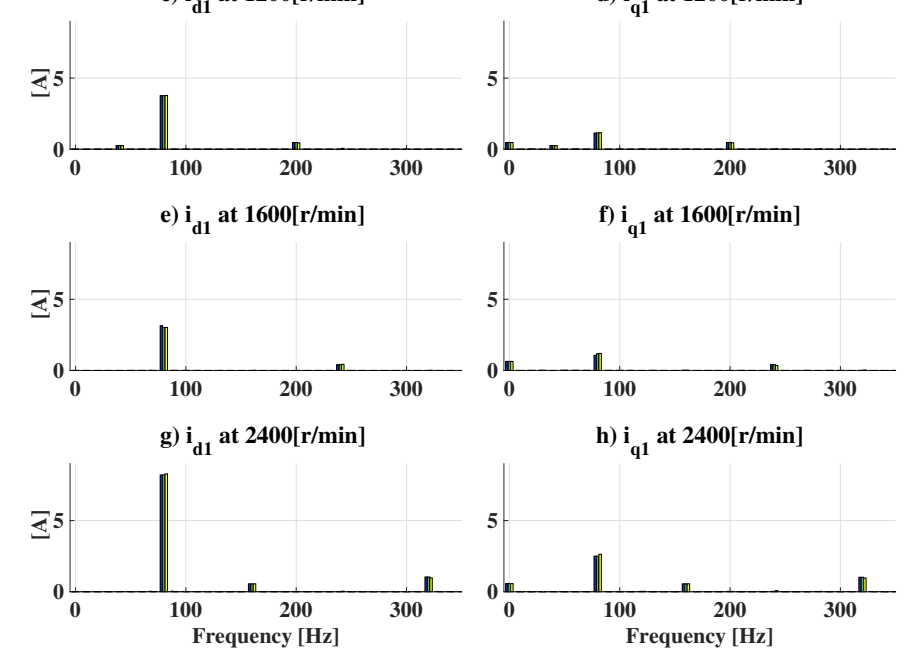

Fig. 16. FFT amplitudes of the measured, reference and analytical $d-q$ axis currents absorbed by sector 1 for the $80[\mathrm{~Hz}]$ vibration compensations.

expressions of the $d-q$ axis reference current with identical harmonic orders content but with different amplitudes and phase angles.

A validation by means of FEA is performed for what concerns the quality of the force produced. The $80[\mathrm{~Hz}]$ vibration suppression at $2400[\mathrm{r} / \mathrm{min}]$ presents the higher force magnitude $\left|F_{k}\right|$, hence the highest magnetic loading condition. Considering it as the case study, the waveforms of the measured $d-q$ axis currents, shown in Fig. 17 a) and b), have been imposed in the FE model of the motor. The resultant force acting on the rotor is presented in Fig. 18 showing a good match between the experimental force reference analytically computed by means of the pseudo-inverse and the FE computed values.

\section{CONCLUSiOnS}

A 6-pole PMSM featuring multi-sector multi-phase winding arrangement has been considered. The machine has been analysed and a novel mathematical model for the electromagnetic torque and radial force production has been carried out. The model obtained results under-determined, hence the pseudo inverse matrix is introduced to define the optimal current reference signals that minimize the copper losses. The 

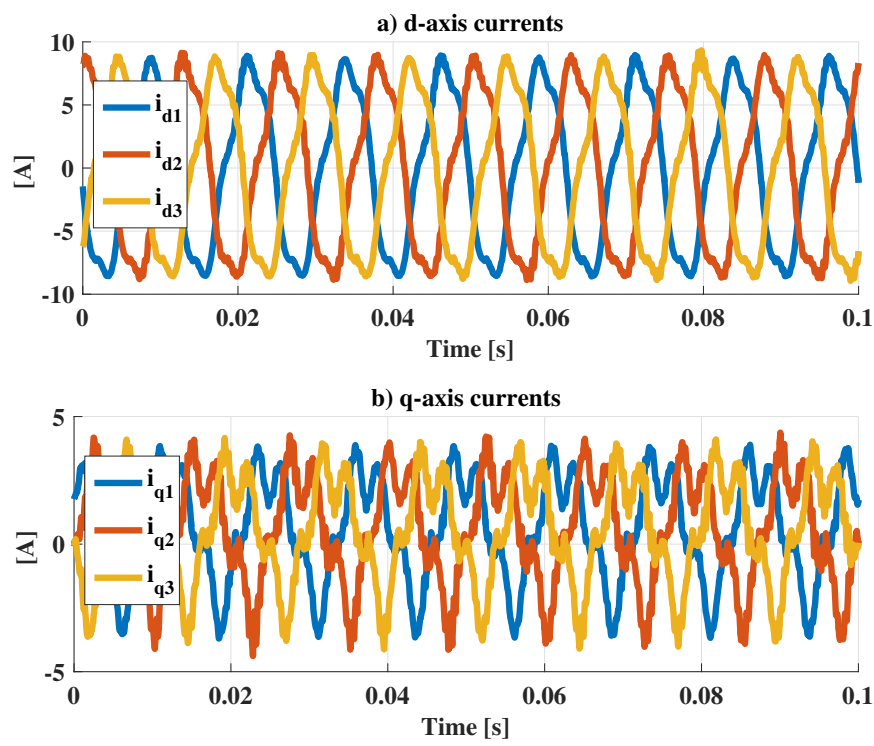

Fig. 17. Measured $d-q$ axis currents absorbed by the three sectors for the $80[\mathrm{~Hz}]$ vibration compensation at $2400[\mathrm{r} / \mathrm{min}]$.

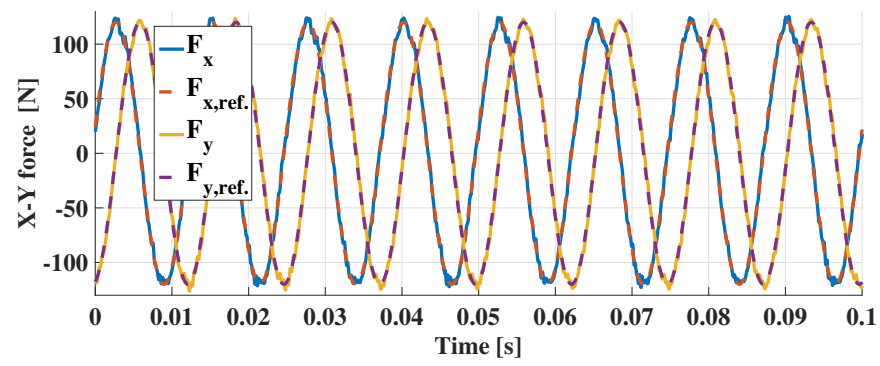

Fig. 18. Rotating force generated supplying the FE model of the MSPM motor with the experimentally measured currents.

capabilities and performances of the proposed method are validated through FEA and an experimental set-up has been built to corroborate the predictions through the compensation of selected vibration harmonics.

The manuscript aims to demonstrate the feasibility of the radial force control method proposed. It has been shown that a controllable radial force can be generated and exploited to suppress selected vibration harmonics. Although the presented work only aims to validate experimentally the proposed radial force control technique, it presents a big potential. As a matter of facts, the same control strategy can be employed to damp the forces that occur when crossing critical frequencies, hence allowing the rotor to achieve high rotating speed. Furthermore, the force control has been implemented in open loop since the acceleration measurement was not available in a form suitable for the control platform. Future works would include the possibility of installing accelerometer transducers that can be connected directly to the control platform allowing the implementation of more complex force control algorithms to suppress multiple vibration peaks. Furthermore, the measurement of acoustic noise variation due to the vibration compensation will be considered for a future investigation.

\section{REFERENCES}

[1] C. Lin, S. Wang, M. Moallem, B. Fahimi, and C. Tschida, "Analysis of vibration in permanent magnet synchronous machines due to variable speed drives," IEEE Trans. on Energy Conv., vol. 32, no. 2, pp. 582-590, June 2017.

[2] C. Ma, Q. Liu, D. Wang, Q. Li, and L. Wang, "A novel black and white box method for diagnosis and reduction of abnormal noise of hub permanent-magnet synchronous motors for electric vehicles," IEEE Trans. on Ind. Electr., vol. 63, no. 2, pp. 1153-1167, Feb 2016.

[3] J. L. Besnerais, "Vibroacoustic analysis of radial and tangential airgap magnetic forces in permanent magnet synchronous machines," IEEE Transactions on Magnetics, vol. 51, no. 6, pp. 1-9, June 2015.

[4] M. Valavi, A. Nysveen, R. Nilssen, R. D. Lorenz, and T. Rlvg, "Influence of pole and slot combinations on magnetic forces and vibration in lowspeed pm wind generators," IEEE Transactions on Magnetics, vol. 50 no. 5, pp. 1-11, May 2014.

[5] M. D. Prieto, G. Cirrincione, A. G. Espinosa, J. A. Ortega, and H. Henao, "Bearing fault detection by a novel condition-monitoring scheme based on statistical-time features and neural networks," IEEE Transactions on Industrial Electronics, vol. 60, no. 8, pp. 3398-3407, Aug 2013.

[6] H. T. Yau, S. Y. Wu, C. L. Chen, and Y. C. Li, "Fractional-order chaotic self-synchronization-based tracking faults diagnosis of ball bearing systems," IEEE Transactions on Industrial Electronics, vol. 63, no. 6, pp. 3824-3833, June 2016

[7] N. Kurihara, J. Bayless, H. Sugimoto, and A. Chiba, "Noise reduction of switched reluctance motor with high number of poles by novel simplified current waveform at low speed and low torque region," IEEE Transactions on Industry Applications, vol. 52, no. 4, pp. 3013-3021, July 2016.

[8] D. Torregrossa, D. Paire, F. Peyraut, B. Fahimi, and A. Miraoui, "Active mitigation of electromagnetic vibration radiated by pmsm in fractionalhorsepower drives by optimal choice of the carrier frequency," IEEE Transactions on Industrial Electronics, vol. 59, no. 3, pp. 1346-1354, March 2012.

[9] X. Chen, J. Wang, and V. I. Patel, "A generic approach to reduction of magnetomotive force harmonics in permanent-magnet machines with concentrated multiple three-phase windings," IEEE Transactions on Magnetics, vol. 50, no. 11, pp. 1-4, Nov 2014

[10] C. Peng, J. Fang, and X. Xu, "Mismatched disturbance rejection control for voltage-controlled active magnetic bearing via state-space disturbance observer," IEEE Transactions on Power Electronics, vol. 30, no. 5, pp. 2753-2762, May 2015.

[11] A. Chiba, T. Fukao, O. Ichikawa, M. Oshima, M. Takemoto, and D. G. Dorrell, Magnetic bearings and bearingless drives. Elsevier, 2005.

[12] T. Baumgartner, R. M. Burkart, and J. W. Kolar, "Analysis and design of a 300-w 500000-r/min slotless self-bearing permanent-magnet motor," IEEE Transactions on Industrial Electronics, vol. 61, no. 8, pp. 43264336, Aug 2014.

[13] A. Chiba, M. A. Rahman, and T. Fukao, "Radial force in a bearingless reluctance motor," IEEE Transactions on Magnetics, vol. 27, no. 2, pp. 786-790, March 1991

[14] X. Sun, Z. Xue, J. Zhu, Y. Guo, Z. Yang, L. Chen, and J. Chen, "Suspension force modeling for a bearingless permanent magnet synchronous motor using maxwell stress tensor method," IEEE Transactions on Applied Superconductivity, vol. 26, no. 7, pp. 1-5, Oct 2016.

[15] W. K. S. Khoo, K. Kalita, and S. D. Garvey, "Practical implementation of the bridge configured winding for producing controllable transverse forces in electrical machines," IEEE Transactions on Magnetics, vol. 47, no. 6, pp. 1712-1718, June 2011.

[16] J. Huang, B. Li, H. Jiang, and M. Kang, "Analysis and control of multiphase permanent-magnet bearingless motor with a single set of halfcoiled winding," IEEE Transactions on Industrial Electronics, vol. 61, no. 7, pp. 3137-3145, July 2014.

[17] B. Li, J. Huang, H. Liu, and Z. Hou, "Analysis and control of sevenphase permanent-magnet bearingless motor with single set of half-coiled winding," in 2014 IEEE 23rd International Symposium on Industrial Electronics (ISIE), June 2014, pp. 2080-2086.

[18] X. L. Wang, Q. C. Zhong, Z. Q. Deng, and S. Z. Yue, "Current-controlled multiphase slice permanent magnetic bearingless motors with opencircuited phases: Fault-tolerant controllability and its verification,' IEEE Transactions on Industrial Electronics, vol. 59, no. 5, pp. 2059-2072, May 2012.

[19] S. Kobayashi, M. Ooshima, and M. N. Uddin, "A radial position control method of bearingless motor based on d - q -axis current control," IEEE Transactions on Industry Applications, vol. 49, no. 4, pp. 1827-1835, July 2013. 
[20] G. Valente, L. Papini, A. Formentini, C. Gerada, and P. Zanchetta, "Radial force control of multi-sector permanent magnet machines," in 2016 XXII International Conference on Electrical Machines (ICEM), Sept 2016, pp. 2595-2601.

[21] Y. Okada, K. Dejima, and T. Ohishi, "Analysis and comparison of pm synchronous motor and induction motor type magnetic bearings," IEEE Transactions on Industry Applications, vol. 31, no. 5, pp. 1047-1053, Sep 1995.

[22] G. Valente, L. Papini, A. Formentini, C. Gerada, and P. Zanchetta "Radial force control of multi-sector permanent magnet machines considering radial rotor displacement," in 2017 IEEE Workshop on Electrical Machines Design, Control and Diagnosis (WEMDCD), April 2017, pp. 140-145.

[23] P. Bolognesi, "A mid-complexity analysis of long-drum-type electric machines suitable for circuital modeling," in 2008 18th International Conference on Electrical Machines, Sept 2008, pp. 1-5.

[24] P. Bolognesi, F. Papini, L. Papini, and O. Bruno, "Effects of saturation on eccentricity force in permanent magnet synchronous machines," in SPEEDAM 2010, June 2010, pp. 324-330.

[25] Z. Q. Zhu, Z. P. Xia, L. J. Wu, and G. W. Jewell, "Analytical modeling and finite-element computation of radial vibration force in fractional-slo permanent-magnet brushless machines," IEEE Transactions on Industry Applications, vol. 46, no. 5, pp. 1908-1918, Sept 2010.

[26] Z. Q. Zhu, M. L. M. Jamil, and L. J. Wu, "Influence of slot and pole number combinations on unbalanced magnetic force in pm machines with diametrically asymmetric windings," IEEE Transactions on Indus try Applications, vol. 49, no. 1, pp. 19-30, Jan 2013.

[27] Z. Q. Zhu and D. Howe, "Instantaneous magnetic field distribution in brushless permanent magnet dc motors. ii. armature-reaction field," IEEE Transactions on Magnetics, vol. 29, no. 1, pp. 136-142, Jan 1993.

[28] A. Galassini, G. L. Calzo, A. Formentini, C. Gerada, P. Zanchetta, and A. Costabeber, "ucube: Control platform for power electronics," in 2017 IEEE Workshop on Electrical Machines Design, Control and Diagnosi (WEMDCD), April 2017, pp. 216-221.

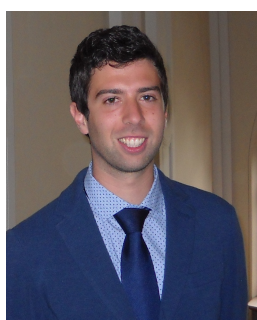

G. Valente received his Bachelor degree in Energy Engineering in 2011 and his Master degree in Electrical Engineering in 2014 both from the University of Padova, Italy. Between 2013 and 2014 he developed sensorless control techniques for PMSM for his Master thesis at the University of Oviedo, Spain. He is now working towards its $\mathrm{Ph} . \mathrm{D}$. with the Power Electronics, Machines and Control Group, University of Nottingham, UK His main research interest is design and control of electrical machines.

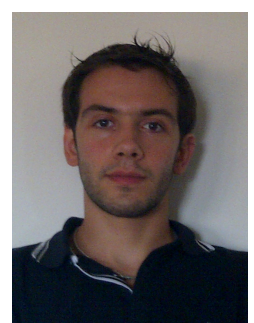

L. Papini received his Bachelor degree (Hons.) and Master degree (Hons.) in Electrical engineering in 2009 and 2011, respectively, both from the University of Pisa, Italy. He's been a visiting student at The University of Nottingham, UK, developing analytical and numerical models for electrical machines. From June to November 2011 he collaborated with the Department of Energy Engineering, University of Pisa, as a research assistant. He is currently working towards its Ph.D. with the Power Electronic, Motors and Drives Group at University of Nottingham. Since 2013 hold a position of research assistant in the same institution. His main research interests are high speed high power density electric machines, machine control and levitating system.

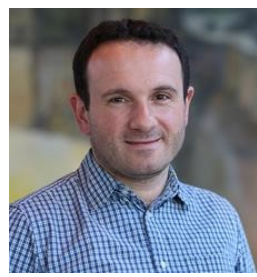

C. Gerada (M 05) received the Ph.D. degree in numerical modelling of electrical machines from The University of Nottingham, Nottingham, U.K., in 2005. He subsequently worked as a Researcher with The University of Nottingham on high-performance electrical drives and on the design and modelling of electromagnetic actuators for aerospace applications. Since 2006, he has been the Project Manager of the GE Aviation Strategic Partnership. In 2008, he was appointed as a Lecturer in electrical machines; in 2011, as an Associate Professor; and in 2013, as a Professor at The University of Nottingham. His main research interests include the design and modelling of high-performance electric drives and machines Prof. Gerada serves as an Associate Editor for the IEEE TRANSACTIONS ON INDUSTRY APPLICATIONS and is the past Chair of the IEEE IES Electrical Machines Committee.

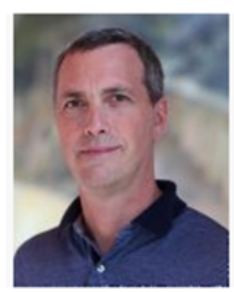

P. Zanchetta (M 00, SM 15) received his MEng degree in Electronic Engineering and his Ph.D. in Electrical Engineering from the Technical University of Bari (Italy) in 1993 and 1997 respectively. In 1998 he became Assistant Professor of Power Electronics at the same University. In 2001 he became lecturer in control of power electronics systems in the PEMC research group at the University of Nottingham UK, where he is now Professor in Control of Power Electronics systems. He has published over 270 peer reviewed papers and he is Senior Member of the IEEE. He is Chair of the IAS Industrial Power Converter Committee IPCC and member of the European Power Electronics (EPE) executive board. His research interests include control of power converters and drives, Matrix and multilevel converters, power electronics for energy and transportation.

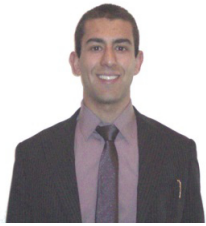

A. Formentini received the M.S. degree in computer engineering and the $\mathrm{PhD}$ degree in electrical engineering from the University of Genova, in 2010 and 2014 respectively. Since 2014 he is research fellow in the Power Electronics, Machines and Control Group, University of Nottingham. His research interests include control systems applied to electrical machine drives and power converters. 